\title{
Litoquímica dos diques máficos de Formiga/Pedro Lessa (Brasil) e Kinga-Comba/Sembé-Ouesso (África): marcadores da tafrogênese toniana no craton São Francisco-Congo Lithochemistry of the Formiga/Pedro Lessa (Brazil) and Kinga-Comba/Sembé-Ouesso (África) mafic dykes: markers of the tonian taphrogenesis in São Francisco-Congo craton
}

Alexandre de Oliveira Chaves ${ }^{1 *}$, Carolina Bueno Menezes ${ }^{1}$, Sara Cirlene de Paula ${ }^{1}$

RESUMO: As similaridades petrográficas e geocronológicas entre os diques máficos de Formiga e Pedro Lessa (Minas Gerais, Brasil) e KingaComba e Sembé-Ouesso (Congo, África) se estendem aos aspectos litoquímicos, segundo os quais eles são idênticos e realmente partes de um mesmo enxame. São todos basaltos toleíticos intraplaca continentais, porém guardam assinatura de basaltos de ilhas oceânicas, reveladora de fonte enriquecida. Esta fonte seria uma pluma mantélica Toniana ou os diques teriam resultado da fusão parcial da cabeça de uma pluma fóssil mais antiga. Os diques investigados registram a tentativa de ruptura extensional litosférica (Tafrogênese) do supercontinente Rodínia no período Toniano. PALAVRAS-CHAVE: litoquímica; diques máficos; Tafrogênese Toniana; Brasil; África.
ABSTRACT: The petrographic and geochronological similarities between Formiga and Pedro Lessa (Minas Gerais, Brazil) and Kinga-Comba and Sembé-Ouesso (Congo, Africa) mafic dykes extend to the lithochemical aspects, by which they are identical and parts of a same swarm. All of them are continental intraplate tholeiitic basalts, but they keep a signature of oceanic islands basalts that reveals a highly enriched source. This source could either be related to a Tonian mantle plume or it could result from partial melting of an oldest fossil plume head. The dykes record a lithospheric breakup attempt (Taphrogenesis) of the Rodinia supercontinent during Tonian.

KEYWORDS: lithochemistry; mafic dykes; Tonian Taphrogenesis; Brazil; Africa.

1'Instituto de Geociências, Universidade Federal de Minas Gerais - IGC-UFMG, Belo Horizonte (MG), Brasil. E-mails: alex2010@ufmg.br; carolina@erm.eng.br; sara_paula@terra.com.br

*Autor correspondente

Manuscrito ID 30034. Recebido em: 23/09/2013. Aprovado em: 23/01/2014 


\section{INTRODUÇÃO}

A Tafrogênese Toniana (1000 - $900 \mathrm{Ma})$ ocorrida no interior do Craton São Francisco-Congo é um processo bem documentado na literatura geológica, marcada por rifteamento, sedimentação, vulcanismo bimodal e injeção de diques máficos (Vicat \& Pouclet 1995, Correa-Gomes
\& Oliveira 2000, Tack et al. 2001, Chaves \& Correia Neves 2005). Quando os continentes Sul-Americano e Africano são reposicionados no Mesozoico em condições pré-deriva anteriores à abertura do Oceano Atlântico Sul, diques máficos Tonianos definem um padrão de alinhamento que configura um verdadeiro enxame dentro de uma área de cerca de 900 por $1400 \mathrm{~km}$ (Fig. 1). O objetivo

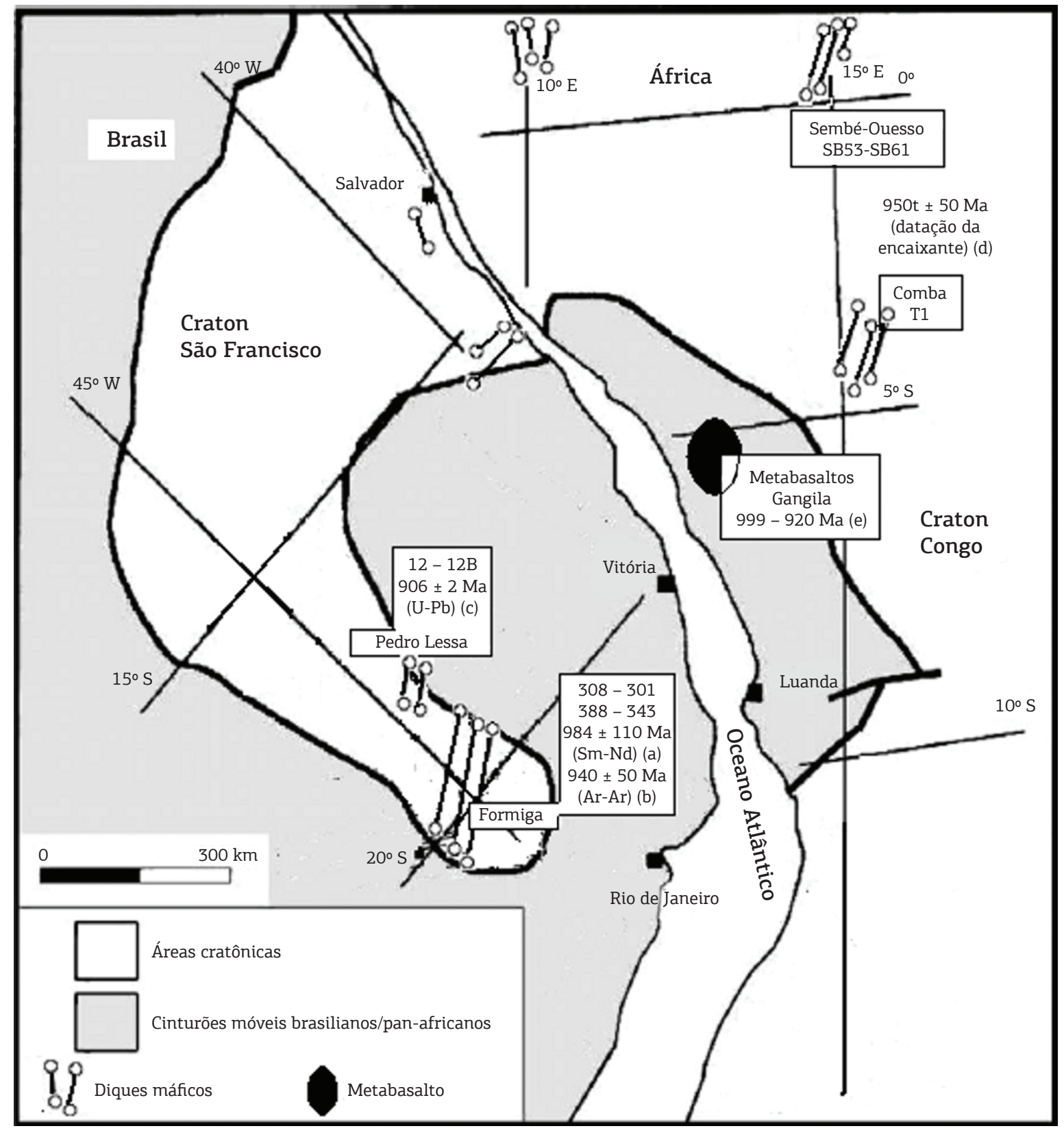

Figura 1. Reposicionamento dos continentes Sul-Americano e Africano em condições pré-deriva anteriores à abertura do Oceano Atlântico Sul (modificado de Chaves \& Correia Neves 2005). Diques máficos Tonianos (1000 - $900 \mathrm{Ma}$ ) definem padrão de alinhamento, configurando um verdadeiro enxame. As amostras de diques investigados neste trabalho e sua localização aproximada estão exibidas. As idades apresentadas para os diques, metabasaltos ou encaixantes foram obtidas de (A) Chaves e Correia Neves (2005), (B) Carneiro e Oliveira (2005), (C) Machado et al. (1989), (D) Vicat \& Pouclet (1995), (E) Tack et al. (2001). 
do manuscrito é apresentar as similaridades litoquímicas entre os diques máficos aflorantes nas regióes de Formiga e Pedro Lessa (Craton São Francisco, Brasil) e Kinga-Comba e Sembé-Ouesso (Craton do Congo, África) como subsídio à constataçáo de que são partes de um mesmo enxame de diques marcador da Tafrogênese Toniana no Craton São Francisco-Congo. Adicionalmente, pretende-se salientar as características da fonte mantélica do referido enxame.

\section{METODOLOGIA}

Foram coletadas quatro amostras de diabásios nos arredores da localidade de Formiga e duas nos arredores de Pedro Lessa, em Minas Gerais, Brasil (Fig. 1). Nos laboratórios do Instituto de Geociências da Universidade Federal de Minas Gerais (IGC/UFMG) foram feitas lâminas delgadas das amostras, as quais foram utilizadas nos estudos micropetrográficos em microscópio polarizador. Após a pulverizaçáo em moinho de panela, as amostras foram enviadas ao Laboratório SGS-Geosol. Ali, os elementos maiores e cinco elementos traços (Ba, $\mathrm{Nb}, \mathrm{Sr}, \mathrm{Y}, \mathrm{Zr}$ ) foram analisados por ICP-OES (espectrometria de emissão óptica com plasma acoplado indutivamente). $\mathrm{Cr}, \mathrm{Ni}, \mathrm{Rb}$ e elementos terras-raras foram analisados por ICP-MS (espectrometria de massas com plasma acoplado indutivamente). A perda ao fogo ocorreu por diferença de peso após aquecimento a $1000^{\circ} \mathrm{C}$. As análises químicas de três amostras de diabásios Tonianos do Congo (África) foram retiradas do trabalho de Vicat e Pouclet (1995), onde a metodologia analítica pode ser verificada. Uma das amostras é proveniente da região de Kinga (Depressão de Comba) e as outras duas são das regióes de Sembé e Ouesso.

\section{GEOLOGIA, IDADE E PETROGRAFIA DOS DIQUES TONIANOS}

Em termos estratigráficos, os diques de Comba e Sembé-Ouesso (África) atravessam o escudo cristalino arqueano, quartzitos e metapelitos paleoproterozóicos e tilitos "inferiores" de $950 \pm 50 \mathrm{Ma}$, porém, não cruzam tilitos "superiores" de cerca de 900 - $850 \mathrm{Ma}$ (Vicat \& Pouclet 1995). Do mesmo modo, os diques de Formiga e Pedro Lessa (Brasil) atravessam o embasamento arqueano, sequencias supracrustais paleo-mesoproterozóicas (Supergrupos Minas e Espinhaço) e não cruzam rochas glaciogênicas do Grupo Macaúbas, de idade neoproterozóica inferior (Chaves \& Correia Neves 2005). Os diques de Pedro Lessa foram datados pelo método U-Pb por Machado et al. (1989) em $906 \pm 2$ Ma e os diques de Formiga mostram idade isocrônica Sm-Nd de $984 \pm$ $110 \mathrm{Ma}$ (Chaves \& Correia Neves 2005) e idade Ar-Ar de $940 \pm 50 \mathrm{Ma}$ (Carneiro \& Oliveira 2005).

Petrograficamente, os diques Tonianos brasileiros e africanos são diabásios (doleritos) com textura ofítica a intergranular e mineralogia constituída por augita (borda uralitizada), plagioclásio saussuritizado, ilmenita, biotita, apatita e quartzo (dados desse trabalho e do artigo de Vicat \& Pouclet 1995). Os diques e soleiras de Pedro Lessa se mostram metamorfisados no fácies xisto-verde devido à Orogenia Brasiliana/Pan-Africana, ocorrida entre 630 - $490 \mathrm{Ma}$.

Próximo à costa oeste Africana, numa região que ficaria situada entre os diques de Kinga-Comba/Sembé-Ouesso e Formiga/Pedro Lessa, afloram meta-basaltos toleíticos tipo CFB (basaltos de derrames continentais) denominados Gangila, com idade entre 999 e $920 \mathrm{Ma}$ (Tack et al. 2001), certamente relacionados à mesma fonte geradora dos referidos diques (Fig. 1). Estes também foram metamorfisados pela Orogenia Brasiliana/Pan-Africana.

\section{LITOQUÍMICA DOS DIQUES TONIANOS}

As composiçóes químicas dos diques Tonianos dos Cratons do São Francisco e do Congo estão apresentadas na Tabela 1. Quando comparados, os teores de todos os elementos investigados em todas as análises se mostram extremamente parecidos. Segundo Vicat e Pouclet (1995), apesar de serem encontrados diques Tonianos no Congo com menos de $2 \%$ de $\mathrm{TiO}_{2}$, a maioria é de alto titânio (ATi), com valores de $\mathrm{TiO}_{2}$ que chegam a $4 \%$. Essa feição é também verificada nos diques Tonianos brasileiros. A média dos valores do número de magnésio (Mg\#) é de 49 para os do Brasil e 46 para os africanos, o que revela para todos eles o mesmo grau de evolução magmática.

Com base nos diagramas TAS (Fig. 2) e $\mathrm{Zr}_{\mathrm{TTiO}}$ versus $\mathrm{SiO}_{2}$ (Fig. 3), todos os diques são basaltos subalcalinos e, segundo o diagrama AFM (Fig. 4), são toleíticos. Em termos tectônicos, são intraplaca de acordo com o diagrama Zr-Ti-Y (Fig. 5). Ainda mais notáveis são as similaridades nos padrôes de terras-raras (ETR) normalizados ao condrito (Fig. 6), com um forte enriquecimento geral em ETR, em molde comparável aos dos basaltos de ilhas oceânicas (OIB - ocean island basalts). Anomalias positivas de európio ou a ausência delas podem ser verificadas.

A semelhança entre os diques Tonianos brasileiros e africanos aparece também no aracnograma de elementos 
incompatíveis normalizados ao manto primitivo (Fig. 7), onde os respectivos padróes também acompanham o tipo OIB. Uma pronunciada anomalia negativa de $\mathrm{Nb}$ é verificada nos diques, evidenciando possível processo de envolvimento crustal. De acordo com o diagrama $\mathrm{Zr}$ versus $\mathrm{Zr} / \mathrm{Y}$ (Fig. 8), a fonte dos diques brasileiros e africanos seria a mesma para ambos, de caráter enriquecido do tipo OIB. Nesse diagrama, o alinhamento das amostras é paralelo ao alinhamento dos processos de fusáo parcial desta fonte, os quais foram preponderantes em relação aos processos de cristalização fracionada do líquido magmático que teria originado os diques. A propósito, as anomalias positivas de Eu na Fig. 6 apontam para a ausência de fracionamento de plagioclásio durante a evolução magmática dos diques.

\section{DISCUSSÕES E CONCLUSÕES}

As semelhanças entre os diques máficos de Formiga e Pedro Lessa (Minas Gerais, Brasil) e Kinga-Comba e SembéOuesso (Congo, África) não se restringem apenas ao alinhamento coincidente entre os diques brasileiros e africanos quando da reconstrução do Craton São Francisco-Congo nas condiçóes pré-abertura do Oceano Atlântico, nem tampouco às similaridades nos aspectos petrográficos e idades Tonianas. Elas se exibem também nas peculiaridades geoquímicas de todos eles e essas peculiaridades reafirmam se tratarem de diques de um mesmo enxame.

Todos os diques são classificados como basaltos toleíticos intraplaca e mostram nítida assinatura de basaltos de ilhas oceânicas (OIB) reveladora de fonte

Tabela 1. Composição química dos diques máficos de Formiga/Pedro Lessa (Brasil) e Comba/Sembé-Ouesso (África). Ferro total expresso como FeOT. Elementos maiores expressos em \% peso e elementos traços e terras-raras em ppm. Número de magnésio (Mg\#) calculado pela razão molar [(MgO)/(MgO+0,85FeOT)]

\begin{tabular}{|c|c|c|c|c|c|c|c|c|c|}
\hline \multirow{2}{*}{$\begin{array}{l}\text { Amostra } \\
\text { Continente }\end{array}$} & 308 & 388 & 301 & 343 & 12 & 12B & SB53 & SB61 & T1 \\
\hline & \multicolumn{6}{|c|}{ Sul-Americano (Minas Gerais - Brasil) } & \multicolumn{3}{|c|}{ Africano (Congo) } \\
\hline Região & Formiga & Formiga & Formiga & Formiga & $\begin{array}{l}\text { Pedro } \\
\text { Lessa }\end{array}$ & $\begin{array}{l}\text { Pedro } \\
\text { Lessa }\end{array}$ & $\begin{array}{c}\text { Sembé-Ouesso } \\
\text { (Vicat e } \\
\text { Pouclet 1995) }\end{array}$ & $\begin{array}{c}\text { Sembé-Ouesso } \\
\text { (Vicat e } \\
\text { Pouclet 1995) }\end{array}$ & $\begin{array}{c}\text { Comba } \\
\text { (Vicat e } \\
\text { Pouclet 1995) }\end{array}$ \\
\hline $\mathrm{SiO}_{2}$ & 49,99 & 49,67 & 51,46 & 50,74 & 46,29 & 46,95 & 47,2 & 48,89 & 47,26 \\
\hline $\mathrm{TiO}_{2}$ & 3,11 & 3,22 & 3,75 & 2,64 & 2,87 & 2,85 & 3,83 & 4,13 & 3,09 \\
\hline $\mathrm{Al}_{2} \mathrm{O}_{3}$ & 13,17 & 12,25 & 13,27 & 13,77 & 14,18 & 13,85 & 12,3 & 12,84 & 17,84 \\
\hline $\mathrm{FeOT}$ & 14,41 & 14,63 & 12,89 & 14,6 & 12,84 & 13,56 & 14,88 & 13,7 & 11,25 \\
\hline $\mathrm{MnO}$ & 0,21 & 0,21 & 0,2 & 0,19 & 0,21 & 0,21 & 0,49 & 0,22 & 0,2 \\
\hline $\mathrm{MgO}$ & 5,77 & 6,44 & 4,68 & 5,53 & 6,75 & 6,21 & 5,5 & 5,72 & 3,49 \\
\hline $\mathrm{CaO}$ & 8,23 & 8,93 & 7,97 & 8,17 & 9,34 & 9,14 & 7,1 & 8,65 & 9,81 \\
\hline $\mathrm{Na}_{2} \mathrm{O}$ & 2,94 & 2,56 & 2,56 & 3,39 & 2,52 & 2,6 & 2,7 & 2,87 & 3,32 \\
\hline $\mathrm{K}_{2} \mathrm{O}$ & 0,88 & 1,27 & 1,77 & 0,56 & 0,69 & 0,62 & 1,2 & 1,14 & 0,65 \\
\hline $\mathrm{P}_{2} \mathrm{O}_{5}$ & 0,79 & 0,52 & 0,85 & 0,61 & 0,56 & 0,53 & 0,5 & 0,48 & 0,49 \\
\hline $\mathrm{P}, \mathrm{F}$ & 0,7 & 0,54 & 0,7 & 0,46 & 1,85 & 2,03 & 2,4 & 0,56 & 1,33 \\
\hline Total & 100,2 & 100,24 & 100,1 & 100,66 & 98,1 & 98,55 & 98,1 & 99,2 & 98,73 \\
\hline Mg\# & 48,3 & 50,6 & 45,8 & 46,9 & 55,1 & 51,6 & 46,3 & 49,3 & 42,0 \\
\hline $\mathrm{Cr}$ & 86 & 81 & 42 & 69 & 20 & 20 & 11 & 41 & 50 \\
\hline $\mathrm{Ni}$ & 65 & 69 & 65 & 67 & 143 & 102 & 54 & 92 & 78 \\
\hline $\mathrm{Rb}$ & 27 & 66 & 42 & 39 & 14 & 14 & 42 & 33 & 21 \\
\hline $\mathrm{Nb}$ & 34 & 39 & 32 & 39 & 18 & 13 & 23 & 29 & 26 \\
\hline $\mathrm{Zr}$ & 295 & 290 & 305 & 330 & 172 & 172 & 224 & 217 & 236 \\
\hline$Y$ & 18 & 22 & 31 & 26 & 31 & 24 & 38 & 34 & 32 \\
\hline $\mathrm{Sr}$ & 547 & 570 & 760 & 514 & 770 & 623 & 525 & 604 & 519 \\
\hline $\mathrm{Ba}$ & 584 & 292 & 580 & 343 & 350 & 381 & 414 & 375 & 321 \\
\hline $\mathrm{La}$ & 30,2 & 38,5 & 43,7 & 35 & 32,7 & 34,9 & 43,31 & 35,45 & 36,94 \\
\hline $\mathrm{Ce}$ & 67,8 & 86,5 & 93,3 & 79 & 70,1 & 59,7 & 92,03 & 74,74 & 67,01 \\
\hline $\mathrm{Nd}$ & 44,9 & 52,8 & 62,5 & 44 & 42,4 & 34,9 & 52,98 & 41,5 & 36,13 \\
\hline $\mathrm{Sm}$ & 8,54 & 13,1 & 11,4 & 8,25 & 8,9 & 7,3 & 13,15 & 10,74 & 11,07 \\
\hline $\mathrm{Eu}$ & 2,89 & 3,28 & 3,47 & 2,78 & 3,69 & 2,8 & 3,74 & 3,14 & 2,74 \\
\hline $\mathrm{Gd}$ & 7,84 & 8,67 & 10,6 & 7,66 & 8,58 & 6,44 & 9,5 & 6,31 & 8,01 \\
\hline Dy & 5,53 & 6,14 & 9,04 & 5,33 & 6,25 & 4,82 & 9,57 & 5,95 & 8,15 \\
\hline $\mathrm{Er}$ & 2,69 & 3,13 & 4,19 & 2,78 & 3,07 & 2,36 & 4,08 & 2,68 & 3,2 \\
\hline $\mathrm{Yb}$ & 2,05 & 2,59 & 3,39 & 2,15 & 2,5 & 2 & 3,07 & 2,45 & 2,63 \\
\hline
\end{tabular}




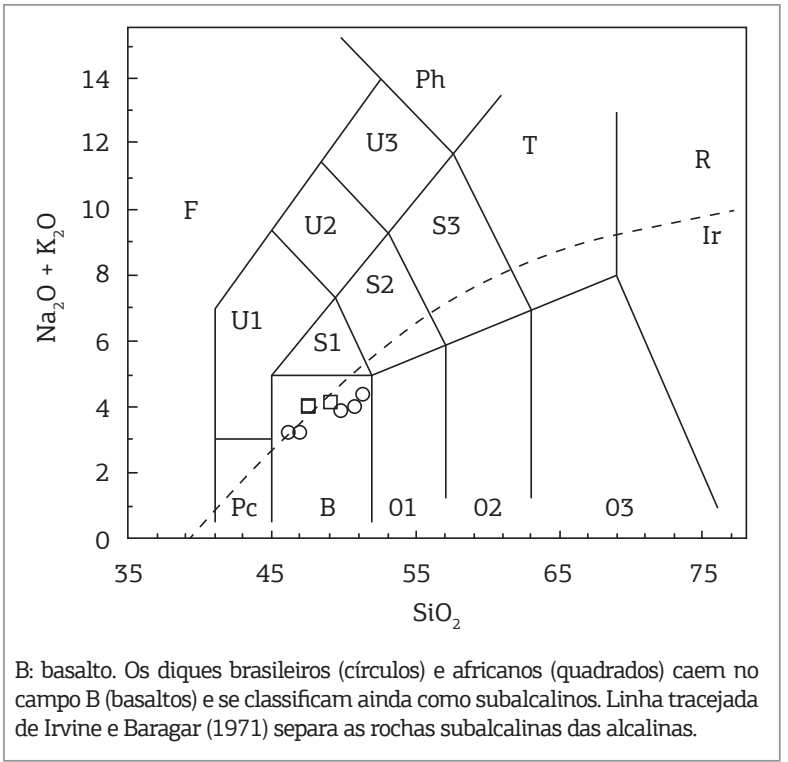

Figura 2. Diagrama Total Álcalis versus Sílica (TAS Le Maitre 2002).

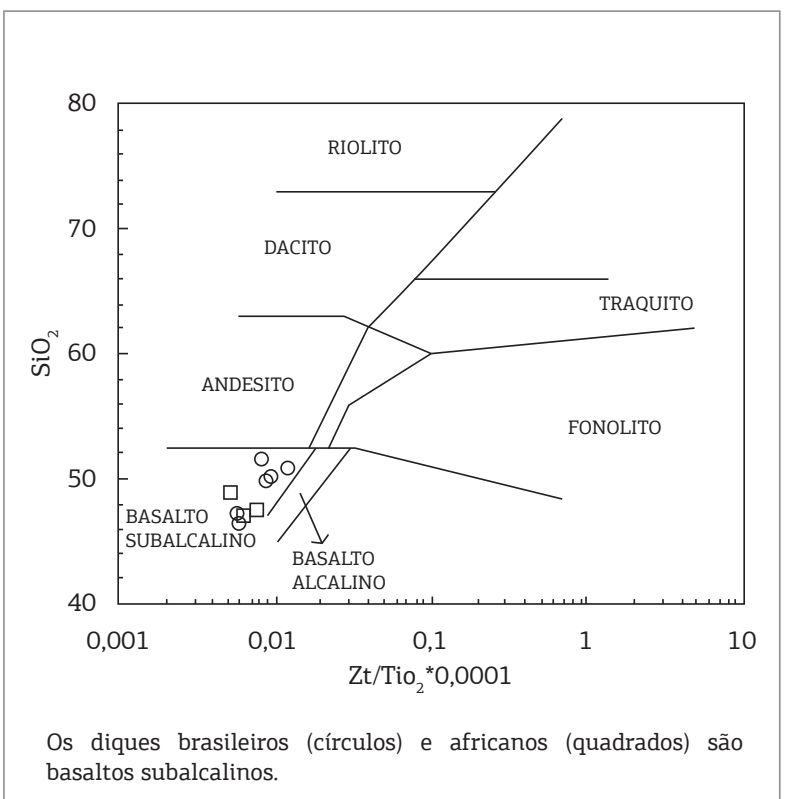

Figura 3. Diagrama $\mathrm{Zr} / \mathrm{TiO}_{2}$ versus Sílica (Winchester \& Floyd 1977).

extremamente enriquecida em elementos incompatíveis. Essa fonte poderia se tratar de uma pluma mantélica Toniana, conforme proposto por Vicat e Pouclet (1995), ou os diques estudados poderiam resultar da fusão parcial (processo revelado na Fig. 8) da cabeça de uma pluma fóssil mais antiga, uma fonte também enriquecida eventualmente preservada sob o Craton do São

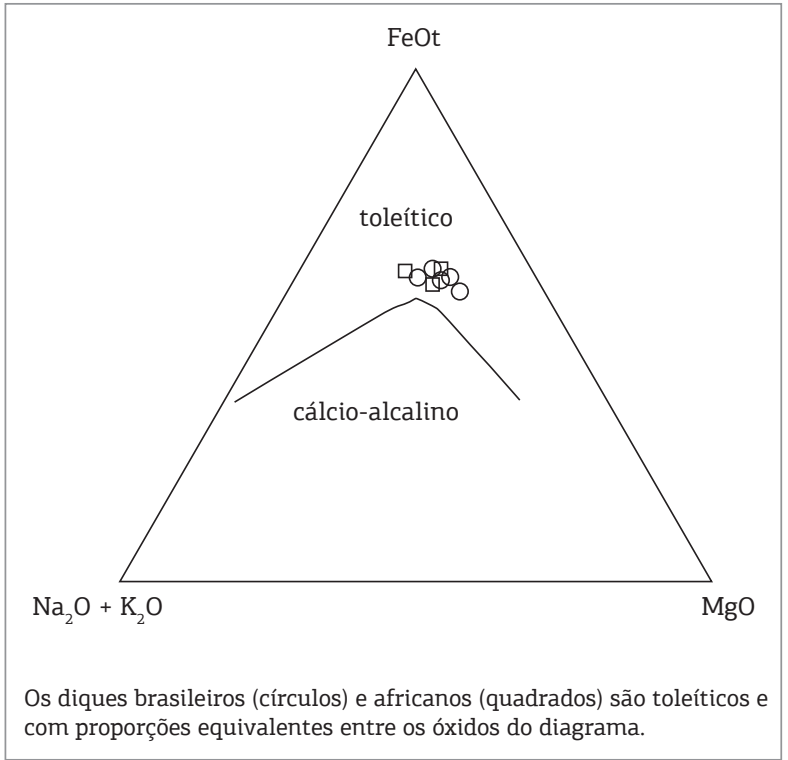

Figura 4. Diagrama ternário AFM (álcalis-FeOT-MgO Irvine \& Baragar 1971).

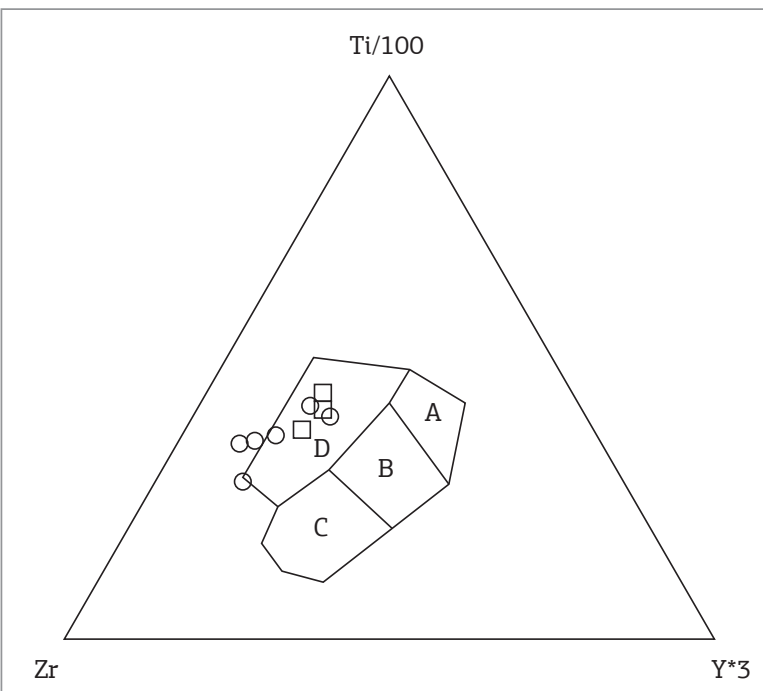

Os diques brasileiros (círculos) e africanos (quadrados) se classificam como basaltos intraplaca (campo D). A: toleítos de baixo K; B: basaltos de assoalho oceânico; C: basaltos cálcio-alcalinos.

Figura 5. Diagrama ternário Zr-Ti/100-Y*3 (Pearce \& Cann 1973).

Francisco-Congo. A propósito, Chaves e Correia Neves (2005) apontam a atividade de uma pluma mantélica Estateriana sob o Craton São Francisco, registrada por diques do enxame Pará de Minas (1,7 Ga). As idades $\mathrm{T}_{\mathrm{DM}}(\mathrm{Sm}-\mathrm{Nd})$ dos diques de Formiga/Pedro Lessa são de cerca de 1,6 Ga (Chaves \& Correia Neves 2005) e parecem suportar essa última hipótese. 


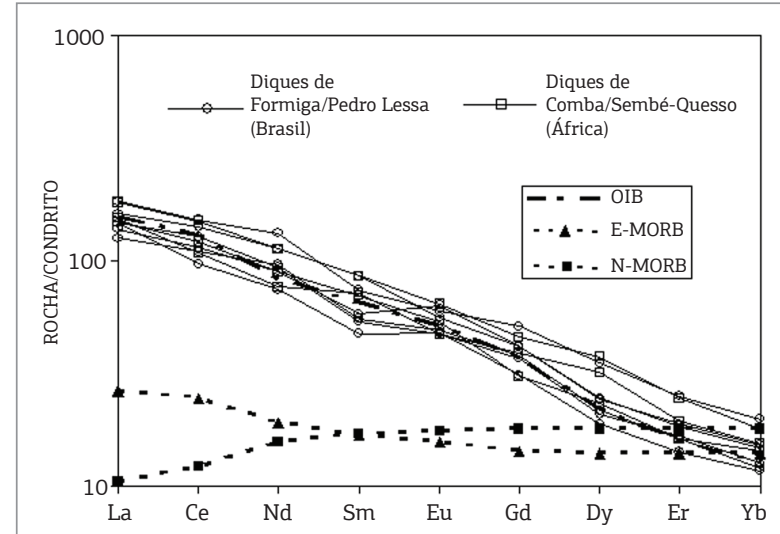

OIB: basaltos de ilhas oceânicas; E-MORB: basaltos enriquecidos de cadeias meso-oceânicas; N-MORB: basaltos normais de cadeias meso-oceânicas.

Figura 6. Aracnograma de elementos terras-raras normalizados ao condrito (normalização segundo Sun \& McDonough 1989).

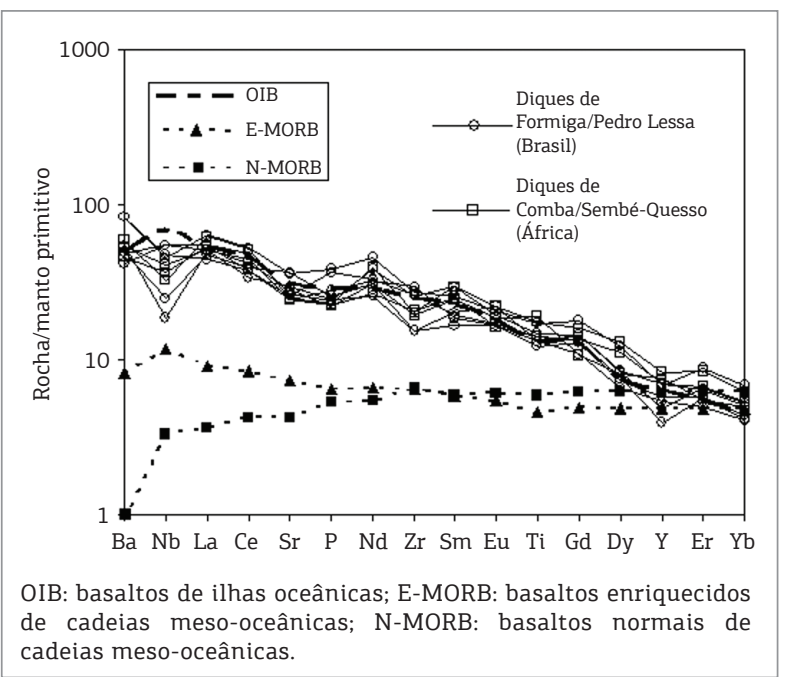

Figura 7. Aracnograma de elementos incompatíveis normalizados ao manto primitivo (normalização segundo Sun \& McDonough 1989).

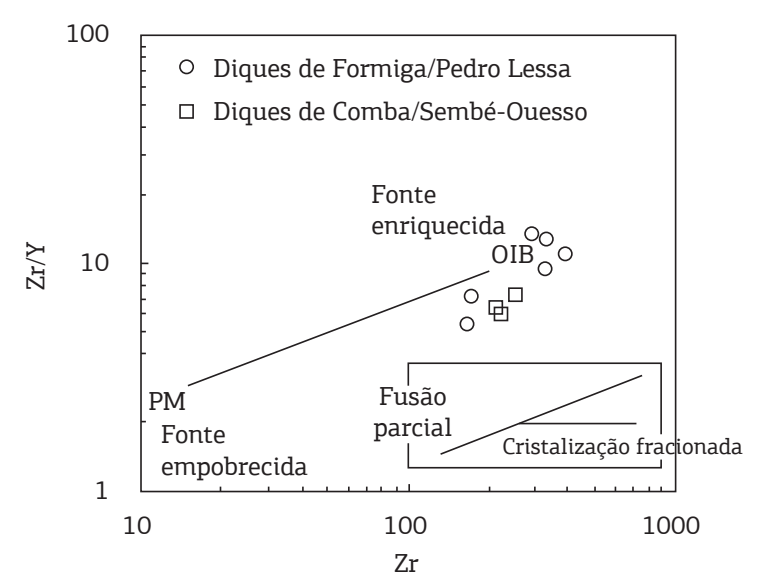

Os diques brasileiros (círculos) e africanos (quadrados) seriam provenientes de fonte enriquecida tipo basaltos de ilhas oceânicas (OIB) e os processos de cristalização fracionada não teriam preponderado na evolução dos mesmos. PM: manto primitivo.

Figura 8. Diagrama binário $\mathrm{Zr}$ versus $\mathrm{Zr} / \mathrm{Y}$ (Sun \& McDonough 1989).

Sendo o Craton São Francisco-Congo uma parte integrante do supercontinente Rodinia, edificado há cerca de 1,0 Ga (Ernst et al. 2013), os diques de Kinga-Comba/SembéOuesso e Formiga/Pedro Lessa, em associação aos metabasaltos Gangila, representam uma tentativa de ruptura litosférica extensional (Tafrogênese) de Rodínia no período Toniano, uma hipótese que já havia sido aventada por Correa-Gomes e Oliveira (2000).

\section{AGRADECIMENTOS}

Ao CNPq (Conselho Nacional de Desenvolvimento Científico e Tecnológico) pela bolsa de produtividade em pesquisa do primeiro autor. À Pró-Reitoria de Pesquisa da Universidade Federal de Minas Gerais pelo apoio financeiro concedido.

\section{REFERÊNCIAS}

Carneiro, M.A. \& Oliveira, A.H. 2005. Tectonic evolution of southern São Francisco Craton: three tectonothermal events based on 40Ar/39Ar isotopic data. III Simpósio do Craton São Francisco. Seção técnica St5-05. CD-ROM.

Chaves, A.O. \& Correia Neves, J.M. 2005. Radiometric ages, aeromagnetic expression, and general geology of mafic dykes from southeastern Brazil and implications for African-South American correlations. Journal of South American Earth Sciences, 19(3):387-397.
Correa-Gomes, L.C. \& Oliveira, E.P. 2000. Radiating 1.0 Ga mafic dyke swarms of Eastern Brazil and Western Africa: evidence of post-assembly extension in Rodinia Supercontinent? Gondwana Research, 3(3):325-332.

Ernst R.E., Bleeker W., Söderlund U., Kerr A.C. 2013. Large Igneous Provinces and supercontinents: completing the plate tectonic revolution. Lithos, 174:1-14. 
Irvine, T.N. \& Baragar, W.R.A. 1971. A guide to the chemical classification of the common volcanic rocks. Canadian Journal of Earth Sciences, 8(5):523-548.

Le Maitre, R.W. 2002. Igneous rocks: a classification and glossary of terms: recommendations of the International Union of Geological Sciences. Sub-commission on the Systematics of Igneous Rocks, Cambridge University Press, $236 \mathrm{p}$.

Machado, N., Schrank, A., Abreu, F.R., Knauer, L.G., Almeida Abreu, P.A., 1989. Resultados preliminares da geocronologia U-Pb na Serra do Espinhaço Meridional, Anais V Simpósio de Geologia de Minas Gerais e I Simpósio de Geologia de Brasília, p.171-174.

Pearce, J.A. \& Cann, J.R. 1973. Tectonic setting of basic volcanic rocks determined using trace element analyses. Earth Planetary Science Letters, 19(2):290-300

Sun, S. \& McDonough, W. 1989. Chemical and isotopic systematics of oceanic basalts: implications for mantle composition and processes. Geological Society, London, Special Publications, 42:313-345.
Tack L., Wingate M.T.D, Liégeois J.-P., Fernandez-Alonso M., Deblond A. 2001. Early Neoproterozoic magmatism (1000-910 Ma) of the Zadinian and Mayumbian Groups (Bas-Congo): onset of Rodinia rifting at the western edge of the Congo craton. Precambrian Research, 110(1):277-306.

Vicat, J-P. \& Pouclet, A. 1995. Nature du magmatisme lie a une extension pre-Panafricaine: les dolerites des bassins de Comba et de Sembe-Ouesso (Congo). Bulletin de la Societe Geologique de France, 166(4):355-364.

Winchester, J.A. \& Floyd, P.A. 1977. Geochemical discrimination of different magma series and their differentiation products using immobile elements. Chemical Geology, 20:325-343.

Arquivo digital disponível on-line no site www.sbgeo.org.br 